\title{
The impacts of using thickened tailings on water management and CAPEX of tailings storage facilities
}

\author{
K Fabian AECOM, USA \\ M Jacobs Goldcorp Inc., Canada \\ A Hooshiar AECOM, Canada \\ E Ngwenya AECOM, Canada
}

\begin{abstract}
The primary goal of water management at mines in arid areas is to minimise the use of surface water and groundwater (natural water) in the mining process. Typical natural water issues include lack of water; access issues due to legal, community, logistic or regulatory reasons; groundwater drawdown; and nearby community and farming impacts. In some cases, large-distance, high-head pumping and/or desalinated water are required, significantly increasing capital and operation expenses (CAPEX and OPEX).

A method of reducing natural water demand is the use of thickened tailings (TT) and paste tailings (PT) technologies, where water is returned from the process plant, minimising discharge to the tailings storage facility (TSF), reducing pumping demand and costs, and thus OPEX. Added benefits of TT and PT include reduced evaporation and seepage losses, further improving water re-use, and reducing impact to groundwater.

An important consequence of the use of TT or PT is an increase of the initial density of tailings discharged to the TSF. This will result in a smaller volume (i.e. lower void ratio) of tailings discharged, therefore less TSF storage capacity required. This can lead to a smaller TSF footprint, and/or lower dam height. Either way, the dam volume is less, and thus the TSF CAPEX is less and the dam can be constructed faster.

This paper discusses the current and planned future TSF operations at Goldcorp's Minera Peñasquito in Mexico. It describes a site water management/balance model and, in particular, the TSF component, and presents natural water demand based on current sand-slime-splitting of tailings. The paper also describes changes to the model and natural water demand reflecting a plan to change tailings discharge from cyclones to $T T$. The main parameters affecting the model are discussed, including results of column settling and constant rate of strain tests to develop initial and final density and void ratio values, and how they affect the volume of tailings discharged and TSF storage capacity required.
\end{abstract}

The paper further discusses the change in the rate of tailings rise, reducing by approximately 22\% per annum over about the same TSF footprint, after the tailings operation changes to TT technology. The effect on the total storage volume and overall dam volume are discussed, demonstrating that the change to TT reduces the required dam volume by $30 \%$, and results in significant CAPEX savings for the TSF expansion.

\section{Introduction}

Mines require water to operate. Without water, the current mineral processing beneficiation technologies cannot operate. Water can be gained from natural sources, such as surface water and groundwater. The beneficiation process segregates the ore into a concentrate suitable for further upgrading and remaining tailings, which contain only residual pay-mineral values. In most cases, tailings are discharged as slurry that carries most of the water used in the milling process.

Most of the water used by a typical metal mine is discharged into the TSF. This water is entrained in the tailings, and is subject to evaporation and seepage losses. It is of great importance to the mine to recover 
as much water as possible from the tailings before it is discharged in order to reduce the water demand from natural sources.

Reducing water in the TSF has many benefits, including reducing the natural (or sometimes referred to as fresh) water demand which is a significant part of the operational expenses of a mine (OPEX), and reduce the overall volume of the TSF, which in turn reduces the capital expenses and sustaining capital expenses (CAPEX). The objective of this paper is to discuss the CAPEX reduction associated with natural water demand reduction using a current, large mining operation - Goldcorp's Minera Peñasquito, Zacatecas, Mexico - where the operation is planned to change to TT.

\section{Water management issues in arid climate mines}

Without water there is no mining. Many of the world's largest metal ore deposits exist in areas of arid climate such as the large gold and copper mines in Chile, Peru, Mexico, United States, Australia and Asia. At these arid mines, securing natural water is of extreme importance. Surface water is rare and groundwater is often deep and far from the mine site.

These conditions often necessitate establishing well-fields and piping water over large distances, some can be $100 \mathrm{~km}$ or more. Mine well-fields often compete with other groundwater uses, such as agriculture or drinking water recovery. Extensive recovery of groundwater may also cause surface subsidence, affecting residences, infrastructure, and agricultural production. The situation is exacerbated by the high rate of evaporation in arid climates. The dry soil under the TSF elevates both evaporation and seepage losses, further increasing the natural water demand. In some cases, the natural water demand of the mine is so pressing that seawater desalination and long-distance piping to high elevations are being considered.

For the last 40 years, tremendous technological advances aimed at recovering water immediately after the beneficiation process has been developed. This water is recycled back into the process instead of discharging it to the TSF. These technologies are generally described as TT or PT technologies, where the solid content of the tailings is increased by reducing the water content of the tailings to be discharged. The use of TT and PT, especially in arid climate mines, is routine. Mines that started operation with slurry tailings can convert to TT or PT technologies, as is the case at Minera Peñasquito.

\section{Current operations at Minera Peñasquito}

Current tailings management at Minera Peñasquito is based on slurry tailings undergoing cycloning to separate sand from fine tailings (slimes). The purpose is to construct the TSF with cycloned sand supported by a downstream waste rock buttress in a (basically) centreline fashion. The 130,000 tpd of tailings discharged from the plant is at about 25 to $30 \%$ solids content; therefore, about $300,000 \mathrm{~m}^{3}$ water is discharged into the TSF each day (see Section 6).

The existing TSF is a U-shaped dam, built on a gentle (2\%) slope toward the west, with dam walls being constructed on the western, northern and southern perimeter. The dam is raised about nine $m$ a year and, over the next two years, it will reach its maximum footprint, necessitating an eastern dam wall essentially creating a permanent footprint ring dike. The current TSF is projected to reach its final build-out in 2017.

The mine operates a robust water recovery system, pumping about $220,000 \mathrm{~m}^{3}$ water from the TSF to the mill (see Section 6). At present, the mine obtains the balance of the water from a nearby Vergel and Torres wellfields. To supplement groundwater availability, a third well field is also under construction $60 \mathrm{~km}$ away. The current life-of-mine plan requires a new TSF or the expansion of the existing TSF by 2018.

Figure 1 shows the existing TSF with its current sand dam operation, and waste rock piles in the background. Figure 2 shows details of the main components of the TSF dam wall and its operations, the use of a cyclone sand tailings platform, which also carries the tailings discharge piping system, and a waste rock buttress on the downstream face of the TSF dam wall. 


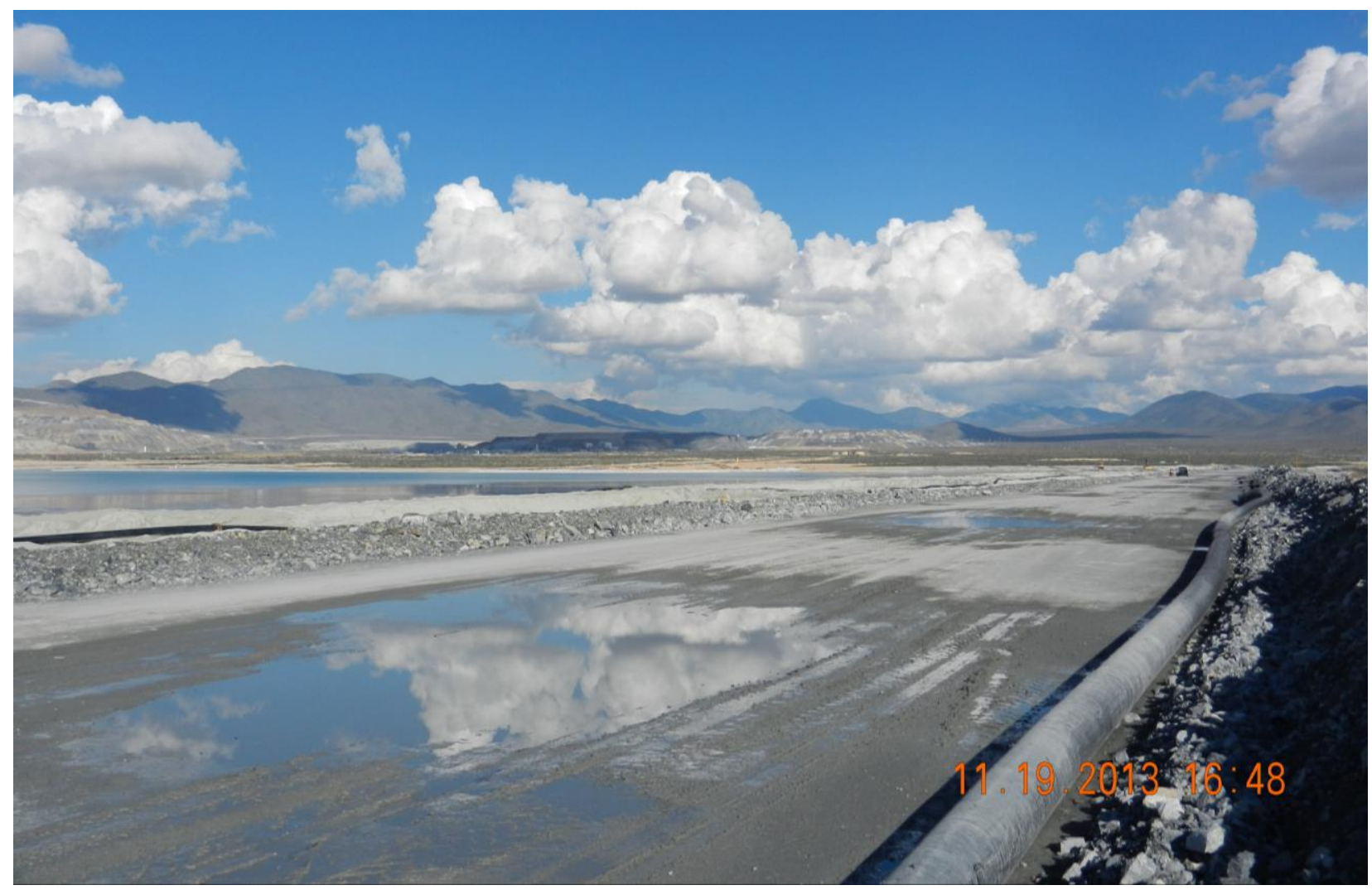

Figure $1 \quad$ Existing TSF at Minera Peñasquito

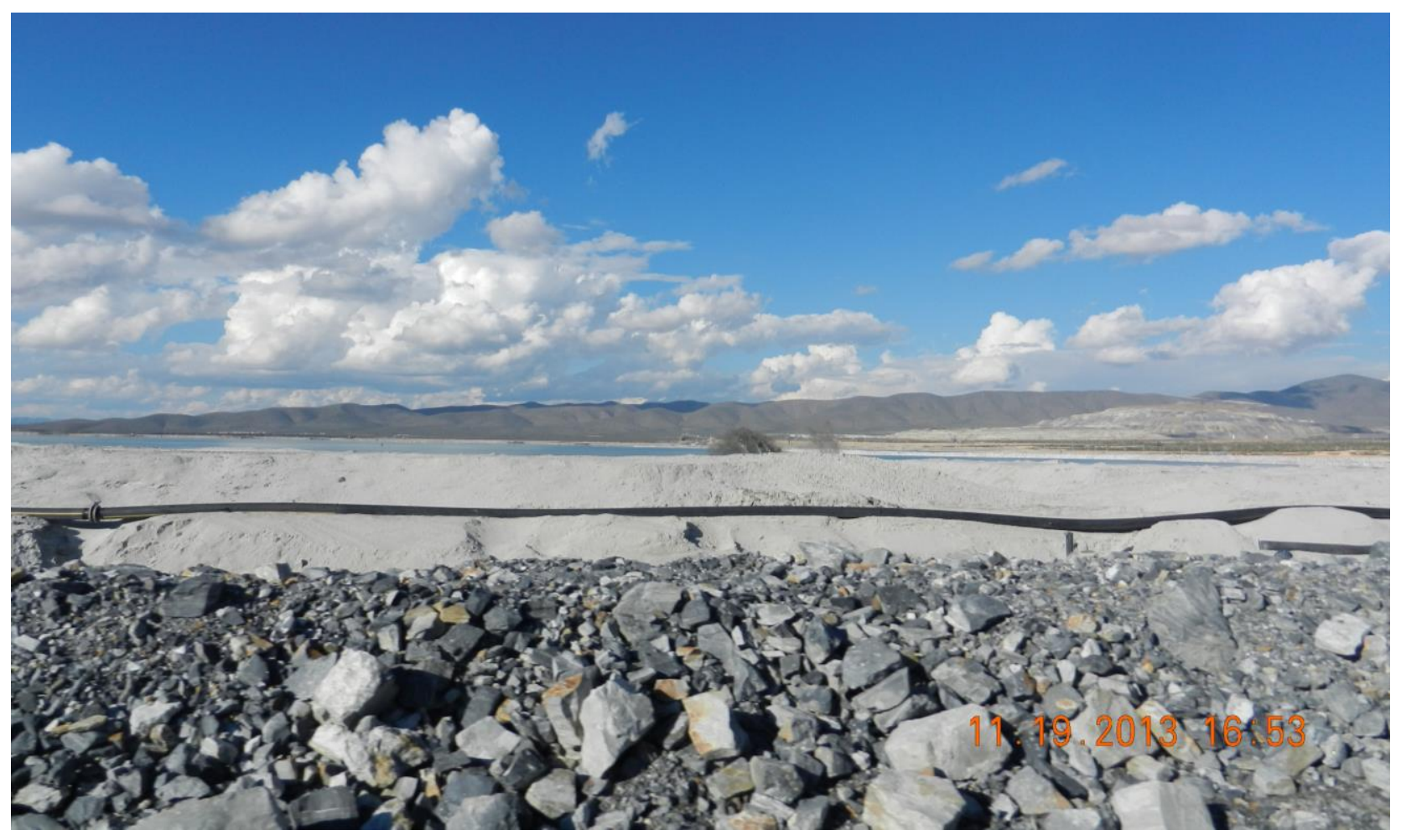

Figure 2 View of waste-rock/sand tailings construction of the TSF

\section{$4 \quad$ Planned changes at Minera Peñasquito}

Goldcorp has been evaluating several site options to expand the existing TSF or to create a new TSF to facilitate extended mining. A pre-feasibility study (PFS) has been conducted to evaluate several options 
(URS Corporation 2014). Parallel to the site evaluation of the various TSF options, Goldcorp is planning to change the tailings management by replacing slurry and cyclone tailings operation with TT technology. The PFS is based on the use of TT.

The TT operation is described in a previous alternative evaluation (Golder Associates 2013), and its highlights are presented here. Tailings samples from various ore-bodies were tested in various laboratories, and considering the relatively high clay content of the tailings, the solids content for the TT operation was established in the 55 to $62 \%$ range. Accordingly, it is planned that 130,000 to 150,000 tpd tailings would be generated at a nominal solids content of $60 \%$ by mass. This represents about $80,000 \mathrm{~m}^{3}$ water to be discharged to the TSF each day.

Section 5 describes laboratory testing performed on $\pi T$ samples manufactured in the laboratory to estimate soil mechanical parameters, such as TT density, porosity, permeability and consolidation. As well as this, it looks at how these parameters affect the overall water balance of the mine and TSF in particular, and the construction quantities of the TSF. In this discussion, one of the options - the vertical expansion of the existing TSF - is considered, since this provides the best comparison between current slurry tailings and future TT operations. Section 6 discusses the changes in water balance as a result of introducing TT technology.

\section{$5 \quad$ Tailings laboratory testing}

\subsection{Sampling}

Minera Peñasquito performed all tailings sampling by following protocols for sampling and handling established by URS. The sampling activity collected approximately 10 litres per hour of tailings slurry from December 28 to 31, 2013, and January 6 to 7, 2014. Several buckets of tailings slurry and jugs of process water were delivered to MEG Consulting Limited (MEG) in Richmond, British Columbia, and to the Instituto Tecnológico de Monterrey (MT) in Monterrey, Mexico. MEG and MT were retained to perform laboratory tests and evaluations on tailings. Two laboratories were retained allow quality control and data verification.

The tailings samples received in both laboratories were observed to be remarkably homogeneous. The solids content was generally in the range of 28 to $33 \%$ by mass.

\subsection{Laboratory testing program and results}

The main objective of the laboratory testing program was to evaluate the self-weight consolidation behaviour and permeability of the $\Pi$ to estimate the TSF capacity and water recovery from the TT. To achieve this objective, the laboratory testing program focused on the following two categories:

1. Characterising/testing 'as-received' tailings slurry samples.

2. Characterising/testing tailings thickened in laboratory conditions.

\subsubsection{Characterising 'as-received' tailings slurry samples (whole tailings with solids content of 28 to $33 \%$ by mass) including determining the following geotechnical parameters}

- Particle-size distribution (PSD) using sieve/hydrometer (see Figure 3).

- Specific gravity.

- Unit weight (performed as a part of a compaction test).

- Atterberg limits (Plasticity index, PI, reported below).

The tailings characterisation results classified as-received tailings slurry samples as 'sandy silty clay' (CL or CL-ML) with clay content of $13 \%$ to $18 \%$, specific gravity of 2.77 to 2.88 , and PI of $6 \%$ to $9 \%$. Figure 3 shows a typical PSD curve. 


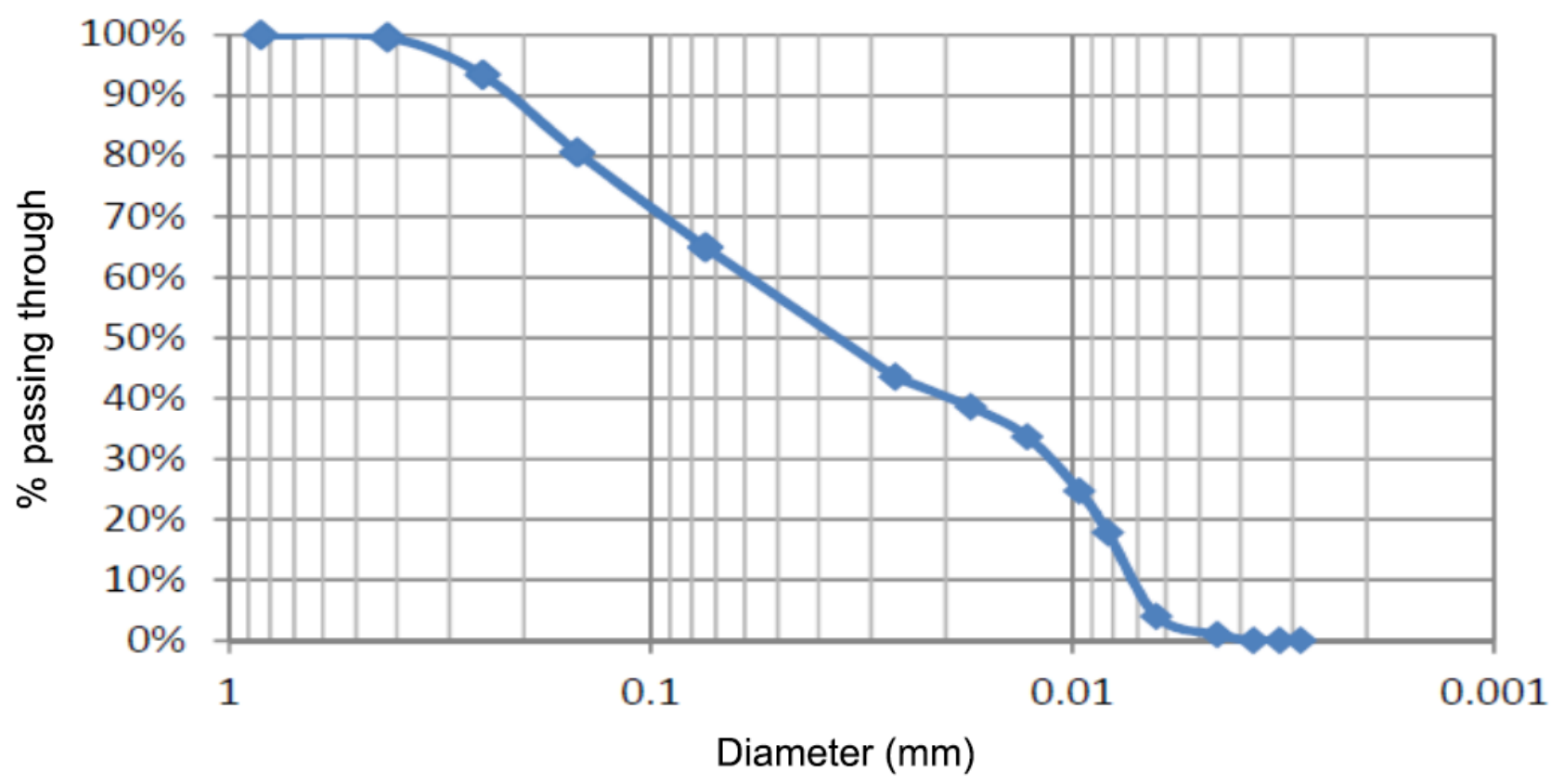

Figure 3 PSD of a typical, as-received tailings slurry sample

\subsubsection{Reducing/thickening the as-received tailings slurry to generate TT under laboratory conditions}

The simulated TT was completed in the laboratory without polymers or chemical agents, and hence the laboratory-thickened samples cannot be considered to exactly represent the actual production. However, the laboratory thickening was performed in a way that the essential characteristics of the tailings, e.g. structure of the clay minerals were not altered.

In the laboratory thickening process, the water content of the as-received tailings slurry was decreased and the solids content was increased to $60 \%$ by mass. Approximately 30 to $40 \mathrm{~L}$ of TT with 60 solids content (by mass) was generated by supernatant decantation followed by air-drying of as-received tailings slurry. The $\mathrm{pH}$, hardness and resistivity of the supernatant were monitored during the thickening process.

\subsection{Testing the thickened tailings}

\subsubsection{Column sedimentation tests}

Column sedimentation tests were performed on six TT samples. Sedimentation for 24 hours resulted in an average water release (i.e. approximate void ratio decrease) of $10 \%$. Water release in a 24 -hour column sedimentation test is considered to be roughly the immediate water release upon tailings discharge (i.e. immediate bleeding of tailings) under normal operation conditions. This is the supernatant that can be recovered immediately after tailings discharge.

\subsubsection{Constant-rate-of-strain (CRS) consolidation tests}

CRS tests (ASTM D 4186 (ASTM International 2012)) were performed on TT samples using load strain rates of $0.5,1,1.5,2,4,6$, and $10 \%$ /hour, as well as maximum effective consolidation stresses of 110,550 , and $2,800 \mathrm{kPa}$. The results indicated that the final void ratio (obtained at the maximum consolidation stress of $2,800 \mathrm{kPa}$ ) ranges between 0.2 and 0.5 (with most tests ending at a final void ratio of 0.4 as shown in Figure 4) and is not very sensitive to the loading strain rates (e.g. Figure 4). Figure 5 shows the hydraulic conductivity versus effective stress correlation. 


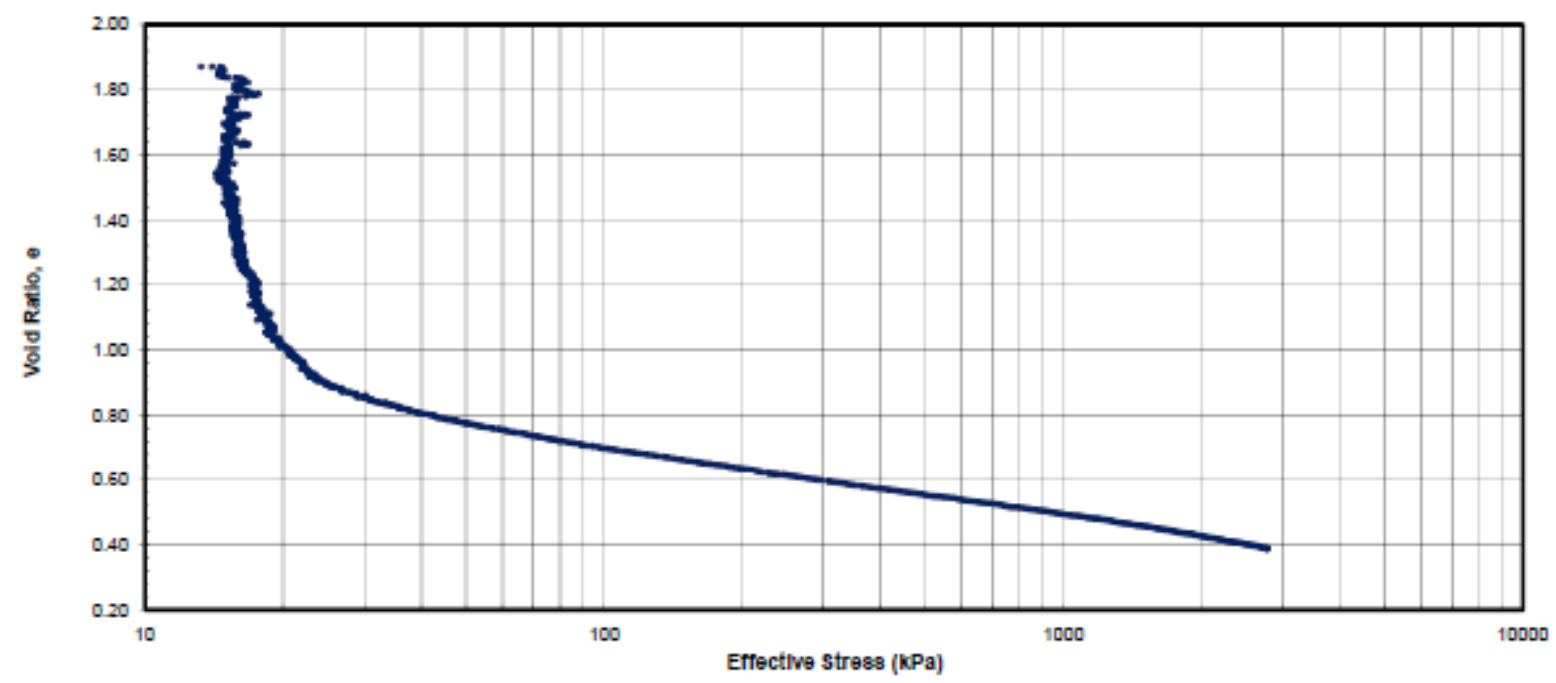

Figure 4 CRS consolidation curve of a representative TT (60\% solids content by mass) sample at effective consolidation stress of $2,800 \mathrm{kPa}$

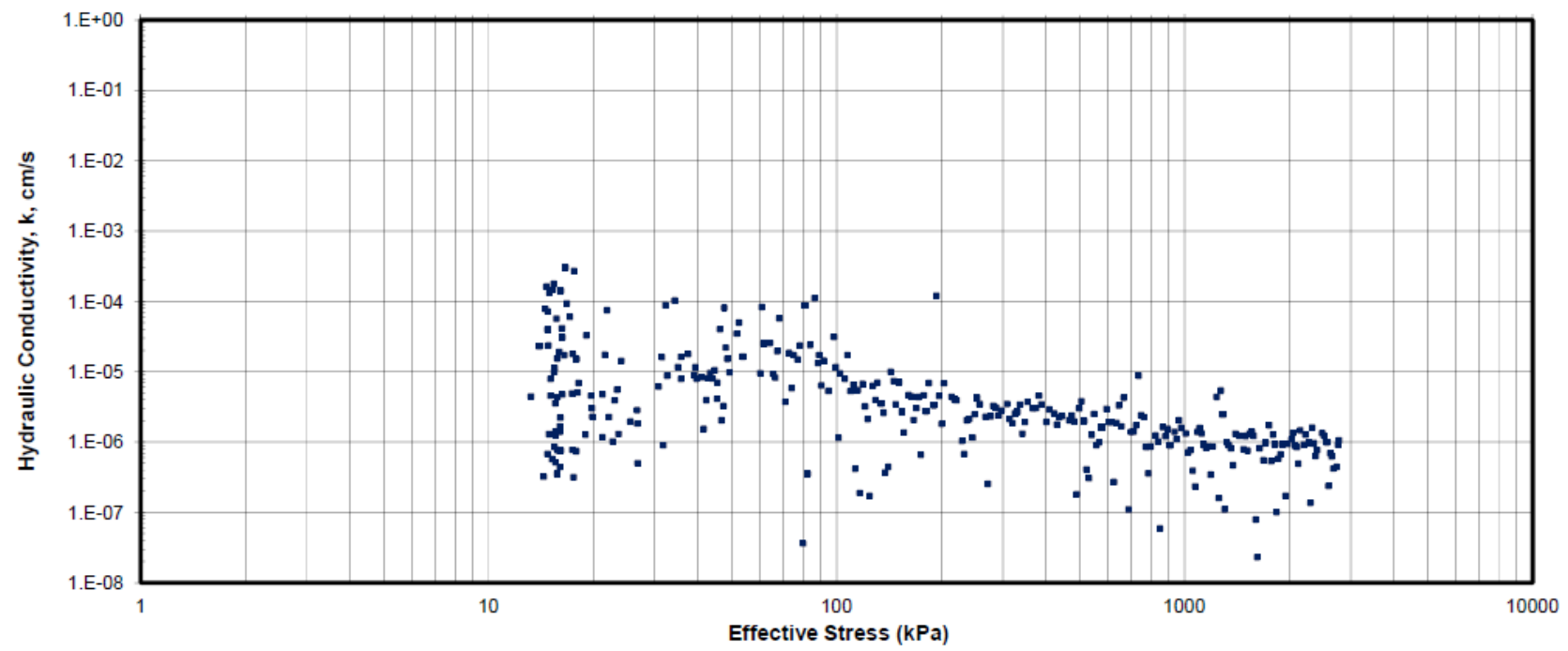

Figure 5 CRS hydraulic conductivity vs. effective stress curve of a representative TT sample (60\% solids content by mass)

Independent of the applied load cell (i.e. stress level), the CRS tests performed the lowest loading strain rate $(0.5 \%$ /hour $)$ showed an initial void ratio of about 1.9 , which agrees well with the theoretically calculated void ratio for a tailings sample with solids specific gravity of 2.8 and solids content of $60 \%$ by mass. A rapid drop in void ratio at the start of the CRS test (stress levels less than $20 \mathrm{kPa}$ ) was observed in all tests.

The calculation of void ratio changes at the start of the CRS (low consolidation stress level) is not an accurate estimate because of the application of a small vertical load. However, an engineering approximation suggests a 0.2 unit drop in void ratio from an initial value of 1.9 under zero applied load. This (about) $10 \%$ drop in initial void ratio agrees well with the column sedimentation results mentioned above.

CRS results also showed that the permeability (hydraulic conductivity) of samples decreases as consolidation effective stress increases (void ratio decreases). The most important observation is that all tested samples reached hydraulic conductivities of $1 \times 10^{-6} \mathrm{~cm} / \mathrm{s}$ (or lower) during the test, although the corresponding effective stress (void ratio) varies among samples. 


\subsubsection{Rigid-wall permeameter tests}

Rigid-wall permeability (ASTM D 5856) tests were performed on selected TT samples after completion of the 250, 500, 1,000, and 2,000 kPa consolidation stages. Minimum and maximum achieved permeabilities at different consolidation stages were $3.2 \times 10^{-10}$ and $1.2 \times 10^{-6} \mathrm{~cm} / \mathrm{s}$, respectively. The results show that 'fully consolidated' tailings can achieve permeability in the order of $1 \times 10^{-6} \mathrm{~cm} / \mathrm{s}$ even under a load of only $1,000 \mathrm{kPa}$ (equivalent of about $70 \mathrm{~m}$ of tailings). The TSF has been built with a low-permeability liner and an underdrain system; however, the low-permeability tailings further improves water recovery and reduces the potential of seepage losses.

\subsection{Discussion}

Column sedimentation test results and engineering approximations from CRS results both suggest an approximately $10 \%$ drop in the initial void ratio ('immediate water release' upon disposal of the TT). CRS and rigid-wall permeameter test results on TT samples both showed that the desired - from the water recovery perspective - hydraulic conductivity $\left(1 \times 10^{-6} \mathrm{~cm} / \mathrm{s}\right)$ is achievable.

\subsubsection{Density}

Water contents and dry unit weight of TT samples were measured and calculated, respectively. It is customary to characterise tailings once it reaches the TSF in terms of density. Based on these results as well as the results of column sedimentation and CRS tests, an initial settled density of $1.12 \mathrm{t} / \mathrm{m}^{3}$ and average consolidated density of $1.33 \mathrm{t} / \mathrm{m}^{3}$ were estimated for TT. This average value was estimated as the average of initial settled density and the final density that is obtained when the full tailings load is reached at the TSF.

\subsubsection{Void ratio reduction due to tailings consolidation}

The vertical stresses under a $5,10,20,40$, or $100 \mathrm{~m}$ layer of tailings with an average density of $1.33 \mathrm{t} / \mathrm{m}^{3}$ are shown in Table 1. The void ratio reduction due to self-consolidation is estimated from the CRS results. The estimated values are based on one-dimensional laboratory CRS consolidation results. However, threedimensional consolidation will be occurring in the TSF. Therefore, this is a conservative approximation of the CRS results that might be obtained in three-dimensional consolidation.

Table 1 Void ratio reduction estimates from One-Dimensional laboratory CRS Results

\begin{tabular}{ccccccc}
\hline Item & Unit & \multicolumn{5}{c}{ Values } \\
\hline Tailings height & $\mathrm{M}$ & 5 & 10 & 20 & 40 & 100 \\
Vertical stress (tailings load) & $\mathrm{kPa}$ & 65 & 130 & 261 & 522 & 1,305 \\
Void ratio reduction (6\%/hour CRS results) & $\%$ & -15 & -20 & -26 & -32 & -42 \\
Void ratio reduction (0.5\%/hour CRS results) & $\%$ & -25 & -23 & -28 & -33 & -61 \\
\hline
\end{tabular}

The time required for complete TT consolidation has not been estimated. The self-weight consolidation of 5 or $10 \mathrm{~m}$ tailings lifts will most likely be completed in less than one year. It is therefore reasonable to assume that the void ratio for each fresh lift of 5 to $10 \mathrm{~m}$ per year of TT will decrease by approximately $20 \%$ before the next lift is deposited. Hence, the average void ratio reduction can be conservatively estimated at less than or equal to $20 \%$. 


\section{$6 \quad$ Water balance modelling}

\subsection{Existing site-wide water balance}

Minera Peñasquito maintains a probabilistic site-wide water balance model. The model was initially created in 2012, as an evolution to a simplified spreadsheet-based model that had previously been in place (Golder Associates 2012). The primary objective of the water balance analysis is to identify mineral processing plant fresh water demands relative to the amount of reclaimable water available at the TSF, well field production capacity, dewatering well supply, climate, operation and process controls, and plant ore process rates.

The existing water balance model is for the current TSF and its cyclone tailings disposal technology. Natural water demand (i.e. freshwater makeup) for the current TSF operation is estimated to be $0.63 \mathrm{~m}^{3} / \mathrm{t}$.

\subsection{Water balance estimates for TT operation}

To estimate freshwater makeup requirements associated with the TT options, modifications were made to the existing site-wide water balance model. The modifications primarily consisted of replacing elements associated with the current cyclone system with a TT representation, and largely associated with the mineral processing plant the thickener and the TSF. Other water uses were assumed to remain constant. The aim of the model modifications was to compare water reclaim (and losses) for TT options.

The modified model was run for each of four TSF expansion site options, and for footprints and conditions at years $2,4,8,12$, and 19 of the TSF life.

Figure 6 shows the main water flows assessed through the modified model, for a TT facility.

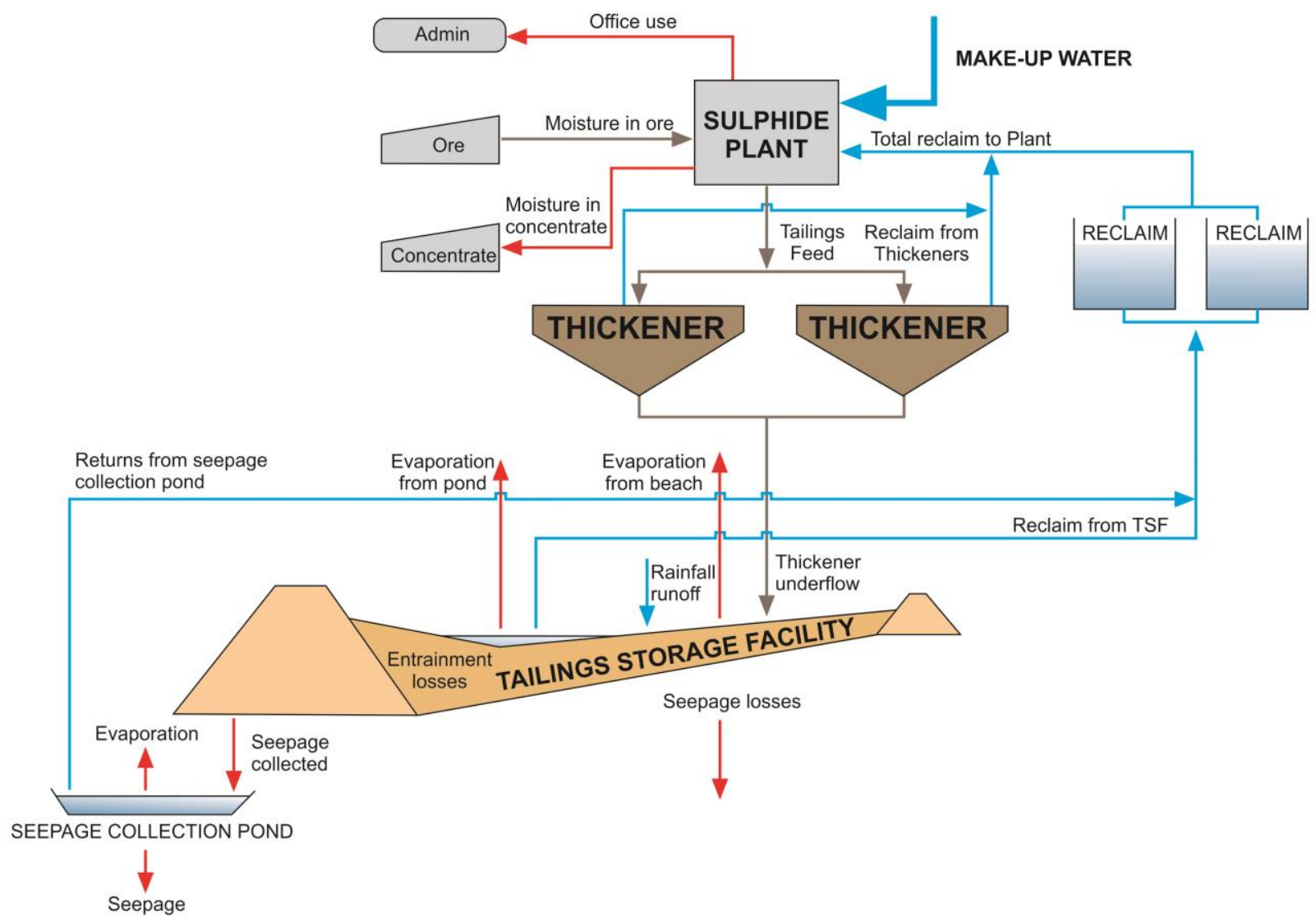

Figure 6 Water balance schematic 


\subsection{Key TT model parameters}

After initial water balance model runs, the model was found to be most sensitive to two key TT parameters:

- Consolidated density values.

- Solids content.

\subsubsection{Consolidated density}

Results from laboratory testing undertaken as part of the PFS were used to estimate model input values for initial settled density, and the consolidated density through the operational years assessed. As discussed in Section 5, an initial settled density of $1.12 \mathrm{t} / \mathrm{m}^{3}$ was estimated, and an average consolidated density of $1.33 \mathrm{t} / \mathrm{m}^{3}$ was assumed for assessments at various stages during the life of TSF.

Additional sensitivity runs were undertaken with average consolidated density values of 1.47 and $1.23 \mathrm{t} / \mathrm{m}^{3}$. $1.47 \mathrm{t} / \mathrm{m}^{3}$ was selected to represent an upper bound in the range of estimated contribution of consolidation water to reclaim, and is the estimated density that is expected when the full tailings load is reached. A value of $1.23 \mathrm{t} / \mathrm{m}^{3}$ was selected as the consolidation resulting from an annual tailings lift, and was selected to represent a lower bound in the range of estimated contribution of consolidation water to reclaim.

\subsubsection{TT solids content}

As mentioned in Section 4, the thickeners that are proposed will operate at a design TT solids content of $60 \%$ (by mass). The $60 \%$ value was used in the baseline model runs.

The tailings output from the thickeners may not be at the PFS-design level of $60 \%$ solids content. Lower solids content would result in additional reclaim water at the TSF, and increased pumping capacity requirements. Higher solids content would result in increased water reclaim from the thickeners and less water reclaim need from the TSF.

The model was run at $62 \%$ and $55 \%$ solids content to test sensitivity. Based on thickener design, the high solids content scenario was tested at $62 \%$ (Golder Associates 2014). To represent an underperforming thickener, $55 \%$ was selected as a representative average value.

\subsection{Model results}

A summary of the results showing a breakdown of key inflows to and outflows from the TSF is presented in Table 2. These are for the $60 \%$ solids TT scenario, for a design ore processing capacity of $115,000 \mathrm{tpd}$, and for tailings exiting the mineral processing plant with a solids content of $25 \%$.

Of $345,000 \mathrm{~m}^{3} / \mathrm{d}$ leaving the mineral processing $265,410 \mathrm{~m}^{3} / \mathrm{d}$ will be returned directly from the thickeners. $75,830 \mathrm{~m}^{3} / \mathrm{d}$ of water will be deposited into the TSF, of which 11,770 to $20,780 \mathrm{~m}^{3} / \mathrm{d}$ could be reclaimed from the TSF pond. The average natural water demand (makeup water usage) ratio was estimated to range between $0.47 \mathrm{~m}^{3} / \mathrm{t}$ and $0.51 \mathrm{~m}^{3} / \mathrm{t}$. The average values shown in the table represent the life-of-mine average. 
Table 2 Breakdown of inflows to and outflows from the TSF

\begin{tabular}{cc}
\hline Water flows & Quantity $\left(\mathbf{m}^{\mathbf{3}} / \mathbf{d}\right)$ \\
\hline Sulphide plant water demand (for 25\% solids slurry) & 345,000 \\
Return directly from the thickeners & 265,410 \\
Sulphide plant losses and water in concentrate & 3,760 \\
Water to TSF & 75,830 \\
Reclaim from TSF pond (monthly average) & 11,770 to 20,780 \\
Fresh water make-up (monthly average) & 49,330 to 61,810 \\
\hline
\end{tabular}

Sensitivity analysis on the consolidated TT density values indicated that that the fresh water usage ratio would remain lower with TT, compared to current levels with the cyclone technology as shown in Table 3.

Table 3 Natural water demand ratios at different average consolidated densities

\begin{tabular}{lccc}
\hline & Density $=1.23 \mathrm{t} / \mathrm{m}^{3}$ & Density $=1.33 \mathrm{t} / \mathrm{m}^{3}$ & Density $=1.47 \mathrm{t} / \mathrm{m}^{3}$ \\
\hline $\begin{array}{l}\text { Natural water } \\
\text { Demand ratio }\left(\mathrm{m}^{3} / \mathrm{t}\right)\end{array}$ & 0.52 to 0.53 & 0.47 to 0.51 & 0.40 to 0.46 \\
\hline
\end{tabular}

The relatively small proportion of reclaim water is illustrated in Figure 7.

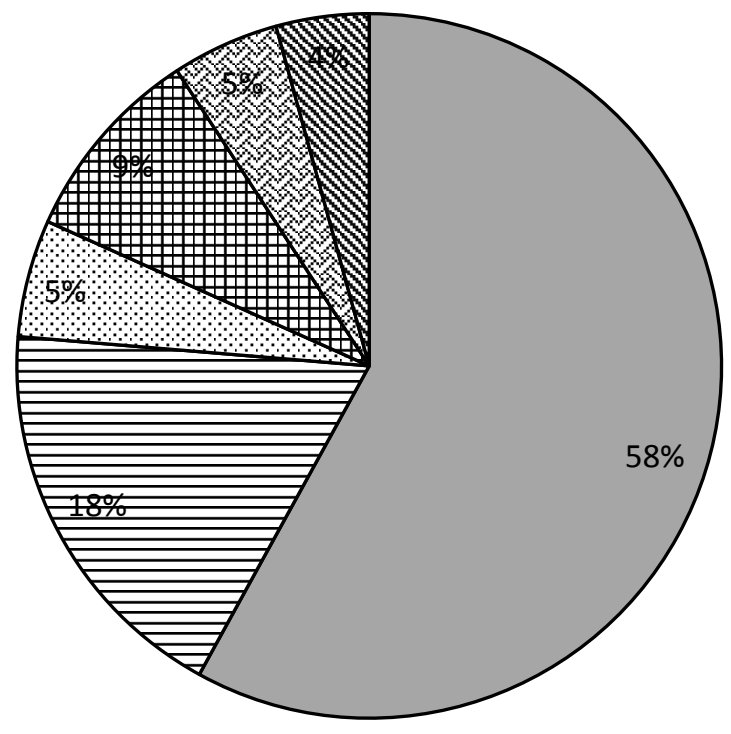

\author{
$\square$ Entrainment in TSF \\ 日TSF Pond Reclaim \\ TTSF Pond Evaporation \\ $\boxplus$ TSF Beach Evaporation \\ 圆TSF Floor Seepage \\ \$ Dam Seepage
}

\title{
Figure 7 Estimated distribution of water at the TSF
}

The reclaim water quantity is shown to be very sensitive to variations in the $\pi$ solids content. With $55 \%$ solids content from the thickener, the reclaim quantities, on average, are nearly double that for $60 \%$ solids TT. With $62 \%$ solids content from the thickener, the reclaim quantities, are about half that for $60 \%$ solids TT. However, total reclaim from the TSF pond, and that direct from the thickeners, remains practically the same in the scenarios assessed. 


\section{$7 \quad$ Tailings dam sizing assessment}

The use of TT and PT technologies has two main functions:

- Return water into the milling process as soon and in as much volume as practical, avoiding seepage and evaporation in the TSF.

- Increase the solids content of the tailings to be discharged.

The TT and PT process reduces the overall water content (or increases the solids content) by the thickening process, resulting in a tailings discharged at a higher density than conventional slurry tailings.

The water balance calculations and CRS tests indicate that TT discharge at Minera Peñasquito would result in an increase of initial density to about $1.12 \mathrm{t} / \mathrm{m}^{3}$. The final settled density of the tailings does not depend on the tailings delivery, since it depends on the geotechnical parameters of the tailings. However, the $T T$ or PT process discharges tailings in a somewhat pre-consolidated - and therefore higher initial density stage.

Based on the civil engineering design performed for the TSF at Minera Peñasquito, the new (TT-based) tailings operation will reduce the annual rate of rise by approximately $22 \%$. This comparison is made for the option where the existing TSF is expanded vertically using a centreline construction method.

Looking at the geometry change or the TSF cross-section, the about $22 \%$ reduction of rate of rise, converts to an about $30 \%$ reduction in annual waste rock volume and earthwork. This is a substantial savings in sustaining CAPEX over a 19-year mine life.

\section{Conclusions}

TT and PT technologies are very important to reduce the natural water demand (i.e. freshwater makeup) of metal mines, especially in arid climates. These technologies return process water from the plant while reducing the amount of tailings water to the TSF subjected to evaporation and seepages losses, hence reducing OPEX costs.

More importantly, TT and PT technologies generate significantly less tailings volume than slurry technologies, inherently resulting in a smaller TSF, which further reduces CAPEX and sustaining CAPEX.

For Minera Peñasquito, the change from tailings slurry disposal to TT technology results in a natural water reduction from 0.63 to about $0.49 \mathrm{~m}^{3} / \mathrm{t}$ (an about $25 \%$ reduction in water costs) together with about $22 \%$ per year reduction in the rate of rise, resulting in an about $30 \%$ reduction of sustaining CAPEX.

The reduction of the dam fill volume and natural water demand makes the Minera Peñasquito operation more profitable, resulting in corporate income, as well as maintaining employment for miners and support personnel. There are, however, other significant benefits.

A smaller TSF represents less environmental impact, fewer disturbances to the natural environment and surrounding communities, and savings with respect to electrical and diesel costs because of reduced pumping volumes.

\section{Acknowledgements}

The authors gratefully acknowledge the permission of Goldcorp Inc. for the publication of this paper, the support of Minera Peñasquito S.A. de C.V. and its mine staff to collect of the tailings samples, the diligent work and suggestions from Goldcorp Inc., AECOM (a merger of the former AECOM Technology Corporation and URS Corporation), MEG Consulting Ltd., and Instituto Tecnológico de Monterrey staff, and the review comments from Mr. Cecil Urlich, Vice President, AECOM.

\section{References}

ASTM International 2012, ASTM D 4186 - Standard Test Method for One-Dimensional Consolidation Properties of Saturated Cohesive Soils Using Controlled-Strain Loading, ASTM International, West Conshohocken. 
ASTM International 2012, ASTM D 5856 - Standard Test Method for Measurement of Hydraulic Conductivity of Porous Material Using a Rigid-Wall, Compaction-Mold Permeameter, ASTM International, West Conshohocken.

Golder Associates 2012, Water/Tailings Project Site-Wide Water Balance Analysis Model - Revision 0, technical memorandum, completed confidentially for Goldcorp, 10 December 2012, Golder Associates.

Golder Associates 2013, Peñasquito Mine Water Tailings Project Optimization Study, completed confidentially for Goldcorp, February 2012, Golder Associates.

Golder Associates 2014, Minera Peñasquito Trade-Off Study, Golder Associates.

URS Corporation 2014, Pre-feasibility Study Report, Minera Peñasquito Tailings Storage Facility Replacement Project, completed confidentially for Goldcorp, September 2014, URS Corporation. 